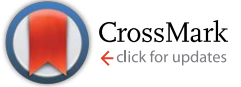

Cite this: RSC Adv., 2017, 7, 742

Received 10th October 2016 Accepted 22nd November 2016

DOI: 10.1039/c6ra25010f

www.rsc.org/advances

\section{The inhibition of H1N1 influenza virus-induced apoptosis by silver nanoparticles functionalized with zanamivir}

\author{
Zhengfang Lin, $\dagger^{a}$ Yinghua $\mathrm{Li}, \dagger^{\mathrm{a}}$ Min Guo, ${ }^{a}$ Tiantian $\mathrm{Xu},{ }^{a}$ Changbing Wang, ${ }^{a}$ \\ Mingqi Zhao, ${ }^{a}$ Hanzhong Wang, ${ }^{b}$ Tianfeng Chen ${ }^{\star c}$ and Bing Zhu ${ }^{\star a}$
}

\begin{abstract}
As one of the most effective drugs for influenza virus infection, clinical application of zanamivir is restricted with the emergence of resistant influenza virus. It is crucial to manufacture novel pharmaceuticals against influenza virus infection. In recent years silver nanoparticles (AgNPs) have attracted wide attention in the antiviral field. In this study, we demonstrated surface decoration of AgNPs using zanamivir (ZNV) with antiviral properties. AgNPs co-delivery of the zanamivir nanosystem was designed to reverse influenza virus resistance. In brief, zanamivir modified AgNPs (Ag@ZNV) inhibited the neuraminidase activity of the H1N1 virus. Moreover, cytopathic effect showed that Ag@ZNV remarkably resisted H1N1 virus-induced apoptosis of MDCK cells, involving DNA fragmentation, chromatin condensation and caspase-3 activation. Ag@ZNV effectively reduced the accumulation of reactive oxygen species (ROS) induced by H1N1 virus and activation of both p38 and p53 signaling pathways. Taken together, our study indicates that Ag@ZNV is a novel promising pharmaceutical against H1N1 influenza virus infection.
\end{abstract}

\section{Introduction}

Influenza viruses which pose a great threat to the public are widespread on the global health system. ${ }^{1}$ There are three types of influenza viruses, A, B and C, causing disease in human beings. Nevertheless, infections of influenza A, which H1N1 belongs to, account for the majority of hospitalizations. ${ }^{2}$ The H1N1 influenza pandemic broke out in 2009 in Mexico and America, extended quickly among humans and led to more than 280000 deaths in the whole world, developing into the first human influenza pandemic in the past 40 years. ${ }^{3-5}$ Influenza A is classified according to its two chief surface proteins, hemagglutinin (HA) and neuraminidase (NA). NA plays a significant role in virus replication. It cleans sialic acid from surfaces of HA, NA and cells and helps progeny viruses separate from host cells. ${ }^{6}$ Studies demonstrated that the 2009 A(H1N1) virus resulted from a series of reassortment events involving swine, avian and human influenza A virus strains, with the NA gene originating from an avian-like Eurasian swine $\mathrm{A} / \mathrm{H} 1 \mathrm{~N} 1$ lineage. ${ }^{7,8} \mathrm{NA}$ inhibitors are a category of antiviral compound

${ }^{a}$ Center Laboratory, Guangzhou Women and Children's Medical Centre, Guangzhou Medical University, Guangzhou, 510120, P. R. China. E-mail: zhubing2016@ hotmail.com

${ }^{b}$ State Key Laboratory of Virology, Wuhan Institute of Virology, Chinese Academy of Sciences, Wuhan, 430071, P. R. China

${ }^{c}$ Department of Chemistry, Jinan University, Guangzhou, 510632, P. R. China. E-mail: Tianfengchen2016@hotmail.com

$\dagger$ Zhengfang Lin and Yinghua Li contributed equally to this work. against influenza viruses, targeting the highly conserved enzymatic site of the NA glycoprotein. ${ }^{9}$ Zanamivir and oseltamivir are commonly used as NA inhibitors that bind within the NAactive pocket and disturb the enzyme reaction. ${ }^{\mathbf{1 0}}$ They are the approved options at present in America for instant interference of influenza virus infection. ${ }^{\mathbf{1 1 , 1 2}}$ However, resistance to the NA inhibitors commonly arises due to amino acid mutations within the NA active sites, either in the framework residues or in the catalytic residues. ${ }^{9}$ NA inhibitor-resistant influenza viruses can be selected rapidly in treated patients or appear without a distinct link to treatments sometimes. ${ }^{13}$ New prophylactic and therapeutic approaches against influenza viruses have kindled great interest of scientists.

Based on the distinctive physical and chemical properties, nanomaterials have become novel in medicine, food industry, and environmental technology. ${ }^{\mathbf{1 4 - 1 6}}$ Among them, silver nanoparticles (AgNPs) have attracted wide attention in biomedical field. Beside of the antibacterial, antifungal and anticancer activities, AgNPs are being explored as antiviral agents in recent years. ${ }^{17-19}$ Accumulated data has reported that AgNPs suppress the replications of respiratory syncytial virus, dengue virus 2 , rift valley fever virus, bean yellow mosaic virus, herpes simplex virus, parainfluenza virus 3 and $\mathrm{H} 3 \mathrm{~N} 2$ influenza virus. ${ }^{20-25}$ Therefore, we are expecting to verify that zanamivir modified AgNPs (Ag@ZNV) has prominent activity to restrain H1N1 virus infection. Reactive oxygen species (ROS) plays an essential role in pathophysiological process of our bodies. ${ }^{26}$ Infections of viruses affect the balance of redox, induce ROS overproduction and lead to apoptosis of host cells. ${ }^{27,28}$ Previous research has 
described that AgNPs induce ROS production to kill cancer cells, ${ }^{17}$ but little is known about the relationship and mechanism between the two in virus infections. In this study, we are aiming to explore how zanamivir modified AgNPs antagonize MDCK cells apoptosis induced by H1N1 influenza virus.

\section{Experimental}

\subsection{Materials}

The Madin Darby canine kidney cell line (MDCK) used for influenza research was purchased from American Type Culture Collection (CCL-34 TM). Influenza A/Hubei/74/2009 (H1N1) was donated by Wuhan Institute of Virology, Chinese Academy of Science. Fetal bovine serum (FBS) and Dulbecco's modified eagle's medium (DMEM) from Gibco were used for cell culture. L-1-Tosylamido-2-phenylethyl chloromethyl ketone (TPCK), zanamivir, vitamin $\mathrm{C}(\mathrm{VC})$, silver nitrate $\left(\mathrm{AgNO}_{3}\right)$, thiazolyl blue tetrazolium bromide (MTT), 4',6-diamidino-2-phenyindole (DAPI), coumarin-6,2', $7^{\prime}$-dichlorofluorescein diacetate (DCFDA) and propidium iodide (PI) were all purchased from Sigma. Lyso Tracker deep red molecular probe was obtained from Invitrogen. The terminal deoxynucleotidyl transferase- mediated dUTP nick end labeling (TUNEL) cell apoptosis assay kit, neuraminidase detection kit, BCA protein assay kit and caspase-3 activity assay kit were acquired from Beyotime Institute of Biotechnology (Shanghai, China). p38, p-p38, p53, pp53, PARP, caspase-3 and $\beta$-actin monoclone antibody were provided from Cell Signaling Technology. Milli-Q water for all experiments in this study was collected from a millipore water purification.

\subsection{Synthesis of AgNPs and Ag@ZNV}

AgNPs were prepared as (Li et al.): ${ }^{17}$ briefly, $0.1 \mathrm{ml}$ of $400 \mu \mathrm{g}$ $\mathrm{ml}^{-1}$ freshly prepared VC solution was added dropwise into $4 \mathrm{ml}$ fresh $400 \mu \mathrm{g} \mathrm{ml}^{-1} \mathrm{AgNO}_{3}$ solution, followed with constant magnetic stirring for $30 \mathrm{~min}$ at room temperature. After that, 32 $\mu \mathrm{l}$ of $100 \mathrm{nM}$ zanamivir was added. The excess $\mathrm{VC}, \mathrm{AgNO}_{3}$ and zanamivir were eliminated by dialysis for $24 \mathrm{~h}$. Then concentration of Ag@ZNV was detected by ICP-AES (inductively coupled plasma-atomic emission spectrometry). ${ }^{29}$ The Ag@ZNV nanoparticles solution was ultrasonicated in a water bath before passed through with a $0.22 \mu \mathrm{m}$ pore size filter. The final concentration of AgNPs was $2.5 \mu \mathrm{g} \mathrm{ml}{ }^{-1}$ and $0.8 \mathrm{nM}$ of zanamivir and the sample was stored at $4{ }^{\circ} \mathrm{C}$.

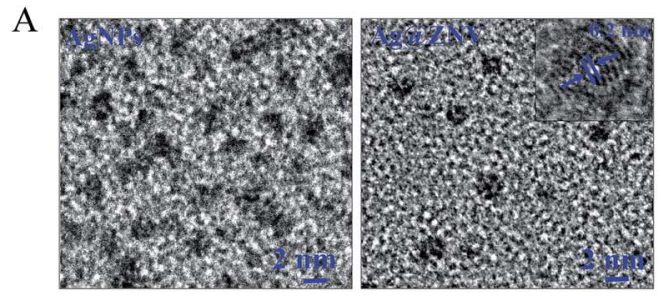

C

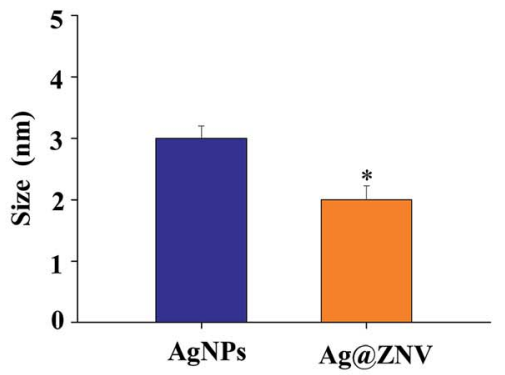

E

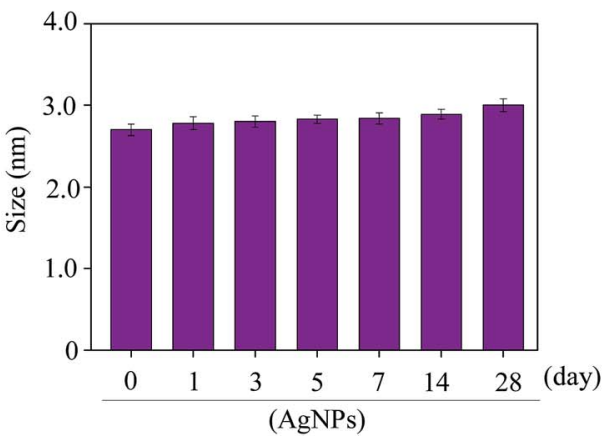

B

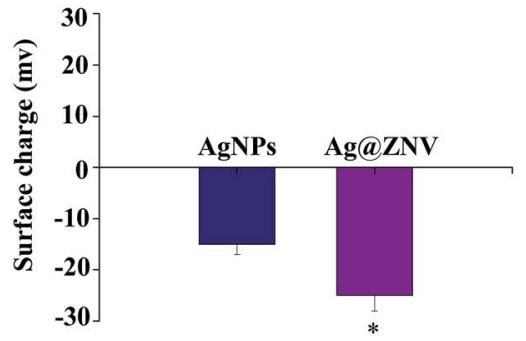

$\mathrm{D}$

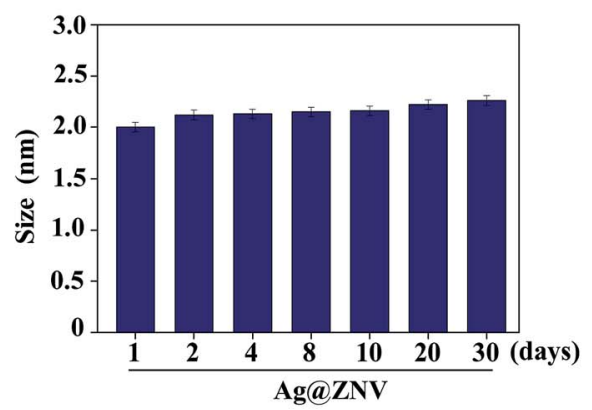

F

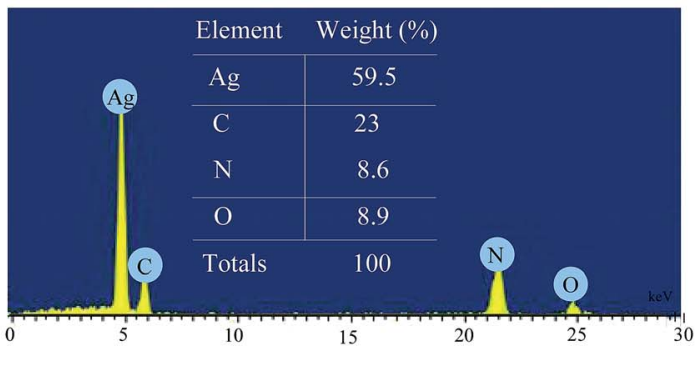

Fig. 1 Characterization of AgNPs and Ag@ZNV. (A) TEM images of AgNPs and Ag@ZNV (scale bar 2 nm). (B) Zeta potentials of AgNPs and Ag@ZNV. (C) Size distributions of AgNPs and Ag@ZNV. (D) and (E) Time course of size distribution of Ag@ZNV and AgNPs in aqueous solutions using a zetasizer nano-zs particle analyzer. (F) EDX analysis of Ag@ZNV. Bars with different characters are statistically different at $P<0.05$ (*) level. 


\subsection{Characterization of Ag@ZNV}

The morphology of Ag@ZNV nanoparticles was characterized by a transmission electron microscopy (TEM). According to the protocol, samples were prepared by dispersing the powder particles onto a holey carbon film on copper grids. The micrographs were acquired using Hitachi (H-7650) for TEM operating at an accelerating voltage of $80 \mathrm{kV}$. Energy Dispersive X-ray (EDX) was carried out using EX-250 system (Horiba) to analyse the elemental composition of Ag@ZNV. Size distribution and zeta potential of Ag@ZNV were determined by Malvern Zetasizer Nano ZS particle analyser. ${ }^{30}$

\subsection{Cell culture and cell infection}

MDCK cells were maintained in DMEM medium with $10 \%$ FBS, $100 \mathrm{U} \mathrm{ml}^{-1}$ penicillin and $50 \mathrm{U} \mathrm{ml}^{-1}$ streptomycin at $37^{\circ} \mathrm{C}$ in $5 \% \mathrm{CO}_{2}$ incubator. ${ }^{31} \mathrm{H} 1 \mathrm{~N} 1$ virus infection was performed and $50 \%$ tissue culture infective dose (TCID50) was calculated as (Amatore et al.). ${ }^{32,33}$ Briefly, cells were seeded in 96-well culture plates at a density of $4 \times 10^{4}$ cells per well for $24 \mathrm{~h}$. Then cells were washed twice with phosphate buffered saline (PBS) and infected with H1N1 in DMEM without FBS. For 50\% tissue culture infective dose (TCID50) test, virus was diluted following 10 times-gradient from 10-1 to 10-10 in this step. After adsorption for $2 \mathrm{~h}$ at $37^{\circ} \mathrm{C}$, the supernatant was removed, and cells were cultured with DMEM containing $2 \%$ FBS and 2 $\mu \mathrm{g} \mathrm{m} \mathrm{m}^{-1}$ TPCK-treated trypsin after washing twice to remove the unattached viruses. The cytopathic effect (CPE) was observed and TCID 50 was calculated using Reed-Muench method. All the H1N1 virus used in this study was at the titer of 100 TCID $50 \mathrm{ml}$.

\section{A}

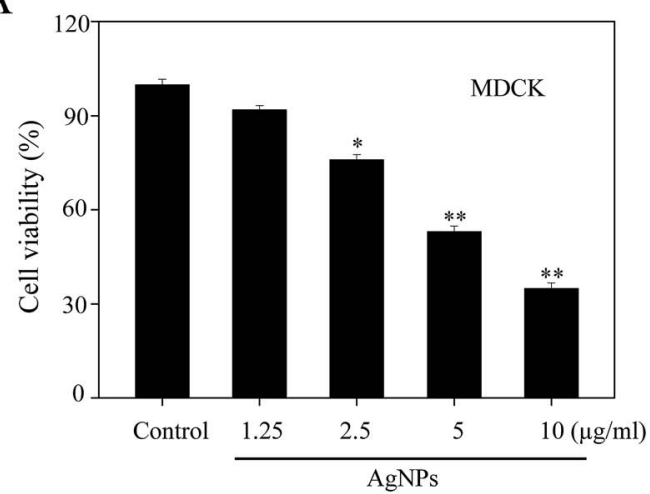

B

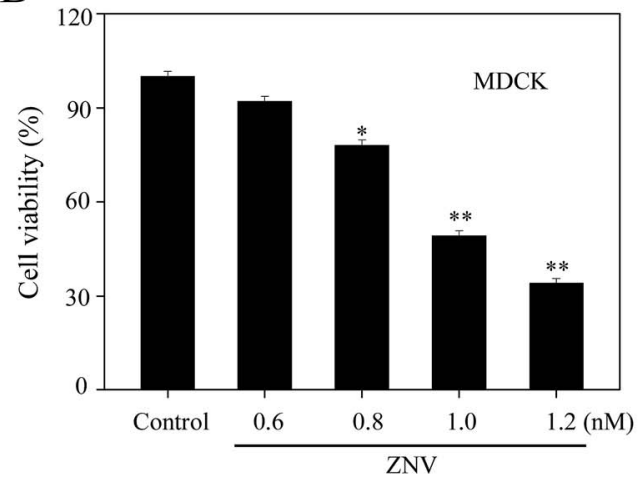

C

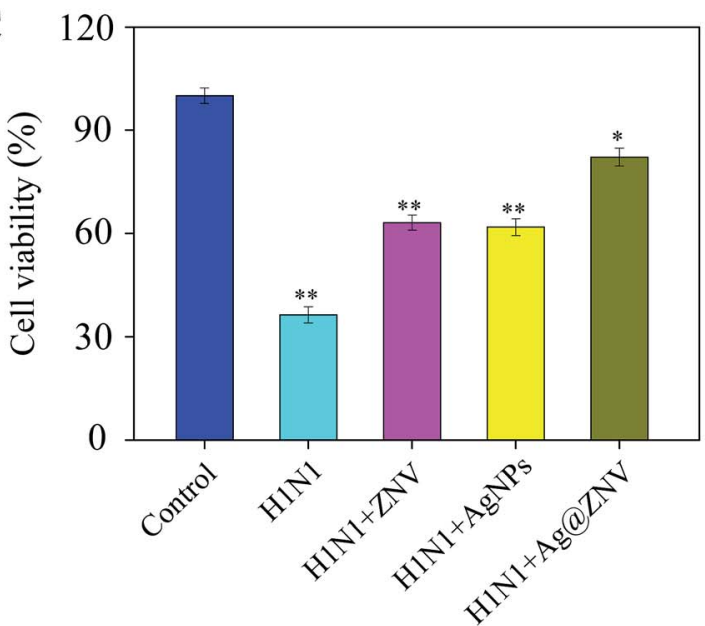

D

Control

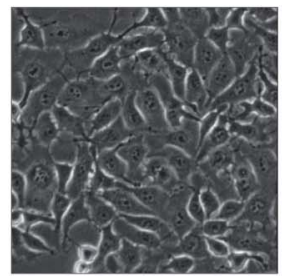

H1N1

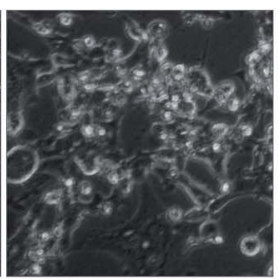

H1N1+ZNV

H1N1+AgNPs

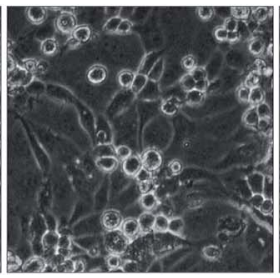

\section{HiN}
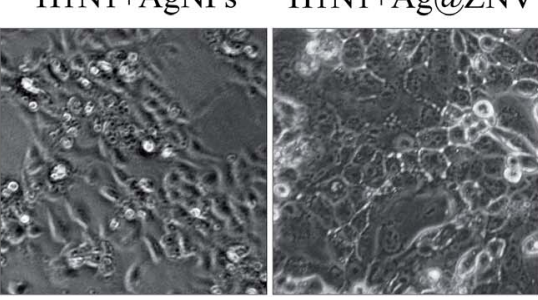

Fig. 2 Effects of Ag@ZNV in MDCK cells infected by H1N1. (A-C) Antiviral activity of AgNPs, ZNV and Ag@ZNV were measured by MTT assay. (D) Morphological changes of MDCK cells observed by phase-contrast microscopy (magnification, $\times 40)$. The concentrations of Ag(ZZNV, AgNPs and ZNV were $2.5 \mu \mathrm{g} \mathrm{ml}^{-1}, 2.5 \mu \mathrm{g} \mathrm{ml}^{-1}$ and $0.8 \mathrm{nM}$. Bars with different characters are statistically different at $P<0.05(*)$ or $P<0.01(* *)$ level. 


\subsection{Determination of cell viability}

Cytotoxicity of Ag@ZNV nanoparticles was determined by MTT assay. ${ }^{34}$ Briefly, MDCK cells were seeded in a 96-well culture plate and infected with H1N1. Then cells were treated with indicated concentrations of zanamivir with or without AgNPs. After $72 \mathrm{~h}, 20 \mu \mathrm{l}$ of $5 \mathrm{mg} \mathrm{ml}^{-1}$ MTT solution was added per well and incubated at $37^{\circ} \mathrm{C}$. Solution in the well was aspirated off after $5 \mathrm{~h}$ and DMSO was added $150 \mu \mathrm{l}$ per well. The absorbance at $570 \mathrm{~nm}$ was recorded and MDCK cell viability against $\mathrm{Ag} @ Z N V$ was measured using a microplate spectrophotometer.

\subsection{Intracellular localization of Ag@ZNV}

The intracellular localization of Ag@ZNV labelled by 6-coumarin in MDCK cells was traced with Lyso Tracker Red as a lysosomal marker. ${ }^{35}$ Briefly, cells were cultured in $35 \mathrm{~mm}$ cell culture dishes with $80 \mathrm{nM}$ Lyso Tracker for $120 \mathrm{~min}$. When $70 \%$ confluence was stained, $1 \mathrm{mg} \mathrm{ml}^{-1}$ DAPI was added for $30 \mathrm{~min}$. Then 6-coumarin labelled Ag@ZNV and Lyso Tracker Red were incubated at $37^{\circ} \mathrm{C}$ for various periods of time. Finally cells were rinsed by PBS three times and analysed by a fluorescence microscope.

\subsection{The neuraminidase inhibition assay}

H1N1 was mixed with or without Ag@ZNV for $2 \mathrm{~h}$ before incubated at $37^{\circ} \mathrm{C}$. Then neuraminidase (NA) activity of influenza virus was determined using a NA detection kit measured by a fluorescence microplate reader with an excitation wavelength $360 \mathrm{~nm}$ and emission wavelength $460 \mathrm{~nm}$ as (Wang et al.). ${ }^{36}$

\subsection{Flow cytometric analysis}

The effect of Ag@ZNV on cell cycle distribution was measured by a flow cytometry as (Song et al.). ${ }^{37}$ MDCK cells infected by H1N1 and treated with or without Ag@ZNV were harvested and fixed with $70 \%$ ethanol at $-20{ }^{\circ} \mathrm{C}$ overnight. After PI staining, DNA contents were quantified and cell cycle distribution was analyzed by MultiCycle software. The proportion of cells in G0/ G1, S, G2/M phases was represented as a DNA histogram.

\subsection{TUNEL and DAPI staining assay}

DNA fragmentation and nucleus condensation were examined with fluorescence staining by a TUNEL apoptosis detected kit and DAPI as (Li et al.). ${ }^{38,39}$ Briefly, after fixed with $3.7 \%$ formaldehyde and permeabilized with $0.1 \%$ Triton X-100 in PBS, the MDCK cells were labeled with TUNEL reaction mixture for $60 \mathrm{~min}$ and with $1 \mu \mathrm{g} \mathrm{ml} \mathrm{m}^{-1}$ of DAPI for $15 \mathrm{~min}$ at $37^{\circ} \mathrm{C}$. The cells were observed under a fluorescence microscope.

\subsection{Caspase-3 activity}

Caspase-3 activity was monitored following the instructions with a caspase- 3 activity assay kit. ${ }^{17}$ Briefly, protein of the cells was extracted following concentration determination using a BCA protein assay kit. Protein mixed with specific caspase-3 substrates Ac-DEVD-pNA was added in a 96-well plate at $37{ }^{\circ} \mathrm{C}$ for $1 \mathrm{~h}$. The absorbance was recorded at $405 \mathrm{~nm}$ wavelength.

\subsection{Measurement of reactive oxygen species (ROS) generation}

ROS accumulation inhibited by Ag@ZNV treated MDCK cells after H1N1 infection was determined by staining cells with DCF assay as (Yang et al.). ${ }^{40}$ Cells were collected and incubated with $10 \mu \mathrm{M}$ DCF-DA in PBS at $37{ }^{\circ} \mathrm{C}$ for $30 \mathrm{~min}$. ROS generation was determined by the fluorescence intensity with excitation and emission wavelengths at $488 \mathrm{~nm} / 525 \mathrm{~nm}$.

\subsection{Western blot analysis}

Expressing of proteins involved in signaling pathways were determined by western blot as (Ren et al.). ${ }^{41}$ MDCK cells treated with or without Ag@ZNV for $24 \mathrm{~h}$ after H1N1 infection were lysed with RIPA buffer and obtained total proteins. The protein concentration was quantified using a BCA assay kit. Then equivalent amount of proteins were separated on sodium dodecyl sulfate (SDS)-polyacrylamide gel followed by transfer onto a PVDF membrane. After being blocked in 5\% skimmed milk, the membranes were incubated with specific primary antibodies and horseradish peroxidase (HRP)-linked secondary antibodies. The bolts were developed with enhanced chemiluminescence (ECL) reagent.

\subsection{Statistical analysis}

All the data were expressed as mean \pm SD. GraphPad Prism 5.0 software was used for data analysis. Data were analyzed using

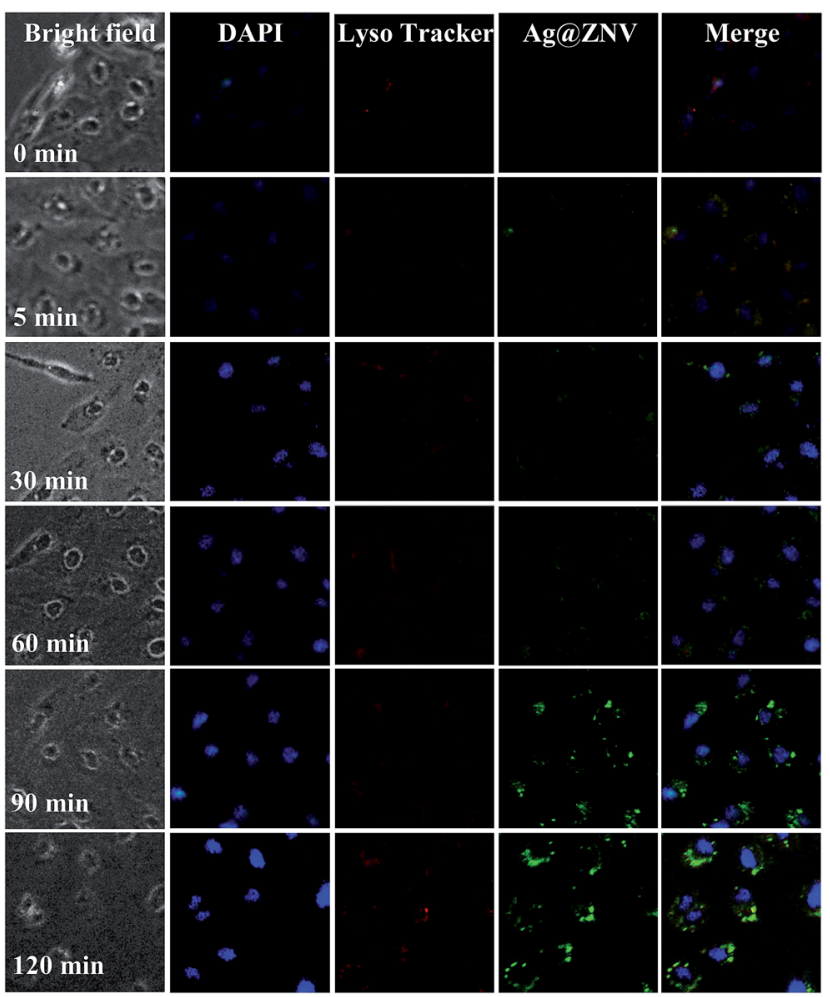

Fig. 3 Intracellular trafficking of Ag@ZNV in MDCK cells. Cells were treated with coumarin- 6 loaded Ag@ZNV for more than 120 min, and stained with Lyso Tracker for lysosome and DAPI for nucleus. Cells were observed under a fluorescent microscope at different time (magnification, $\times 100$ ). 


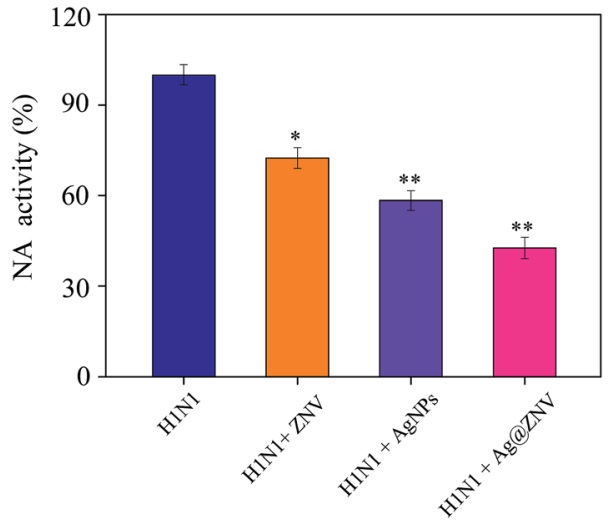

Fig. 4 Inhibition of H1N1 NA activity by Ag@ZNV. The NA inhibition assay was performed by quantifying the fluorescent using a microplate reader. Bars with different characters are statistically different at $P<$ $0.05(*)$ or $P<0.01(* *)$ level. The concentrations of Ag@ZNV, AgNPs and ZNV were $2.5 \mu \mathrm{g} \mathrm{ml}^{-1}, 2.5 \mu \mathrm{g} \mathrm{ml}^{-1}$ and $0.8 \mathrm{nM}$.

two-tailed Student's $t$-test to evaluate differences between two groups or one-way analysis of variance (ANOVA) for multiple group comparisons. Differences were considered statistically significant with $P<0.05\left(^{*}\right)$ or $P<0.01(* *)$.

\section{Results and discussion}

\subsection{Preparation and characterization of Ag@ZNV}

The morphology of AgNPs and Ag@ZNV was firstly characterized by TEM. As was shown in Fig. 1A, Ag@ZNV presented monodisperse and spherical particles with high uniformity. Besides, as average particle size distribution shown in Fig. 1C, $\mathrm{Ag} @ Z N V$ was effectively decreased from $3 \mathrm{~nm}$ to $2 \mathrm{~nm}$ compare to AgNPs. The small size of Ag@ZNV contributed to the highly stable nanostructures and it made it easy to cross cell membrane. In Fig. 1B, the zeta potential of AgNPs alone was $-15.2 \mathrm{mV}$ and increased to $-24.7 \mathrm{mV}$ after loading zanamivir, which explained the higher stability of Ag@ZNV. Furthermore, size distribution of Ag@ZNV in Fig. 1D showed that the average size of Ag@ZNV was between $2 \mathrm{~nm}$ to $2.3 \mathrm{~nm}$ and kept stable for 30 days. Meanwhile, we also detected the size distributions of AgNPs in Fig. 1E. The size of AgNPs was between $2.0 \mathrm{~nm}$ to $3.0 \mathrm{~nm}$ and kept stable for 28 days. In Fig. $1 \mathrm{~F}$, an elemental composition analysis employing EDX showed the presence of a strong signal from the $\mathrm{Ag}$ atoms (59.5\%), together with $\mathrm{C}$ atom signal $(23 \%), \mathrm{N}(8.6 \%)$ and $\mathrm{O}(8.9 \%)$ that from ZNV. No obvious peaks for other elements or impurities were observed. The present of $\mathrm{N}$ and $\mathrm{O}$ atom indicate that ZNV has self-assembled on the surface of AgNPs. Based on the results of EDX analysis,

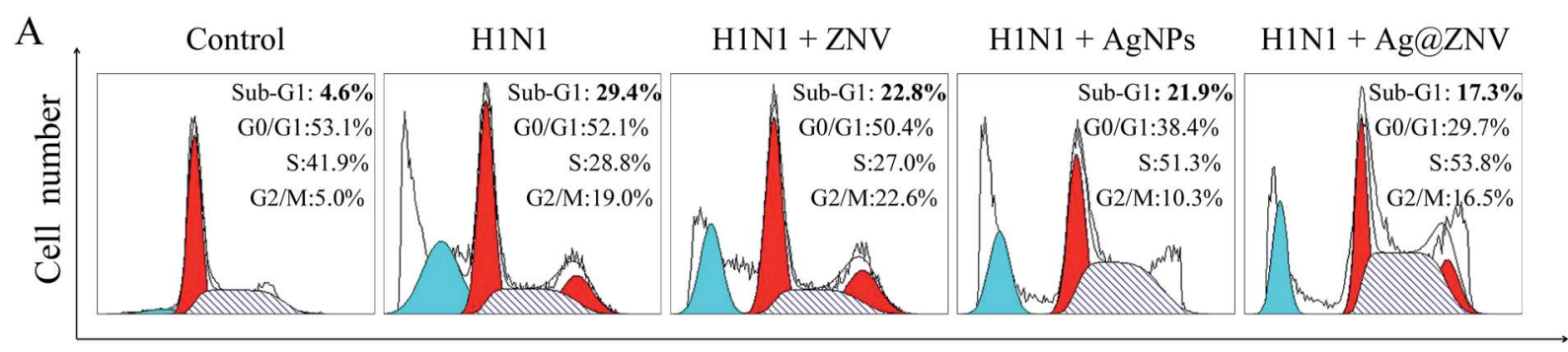

DNA content

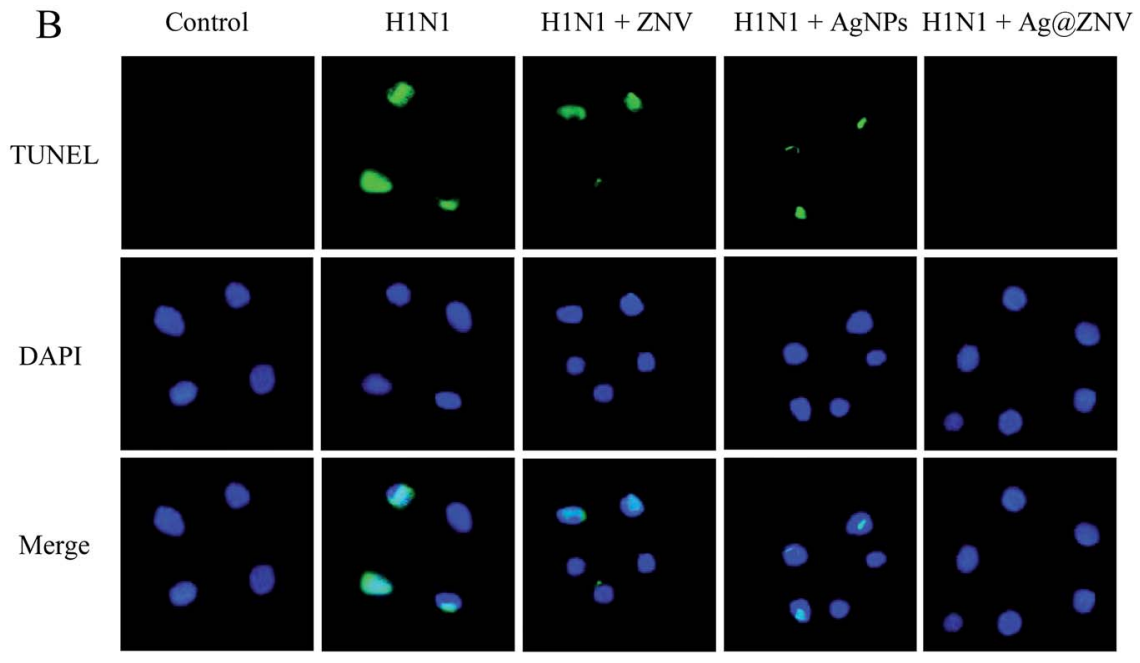

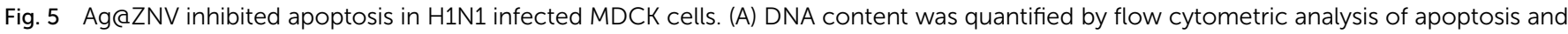

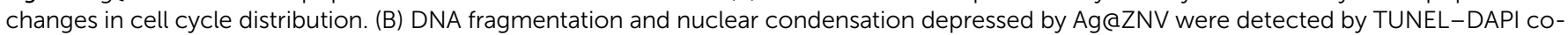

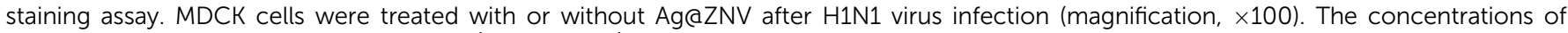
Ag@ZNV, AgNPs and ZNV were $2.5 \mu \mathrm{g} \mathrm{ml}^{-1}, 2.5 \mu \mathrm{g} \mathrm{ml}^{-1}$ and $0.8 \mathrm{nM}$. 


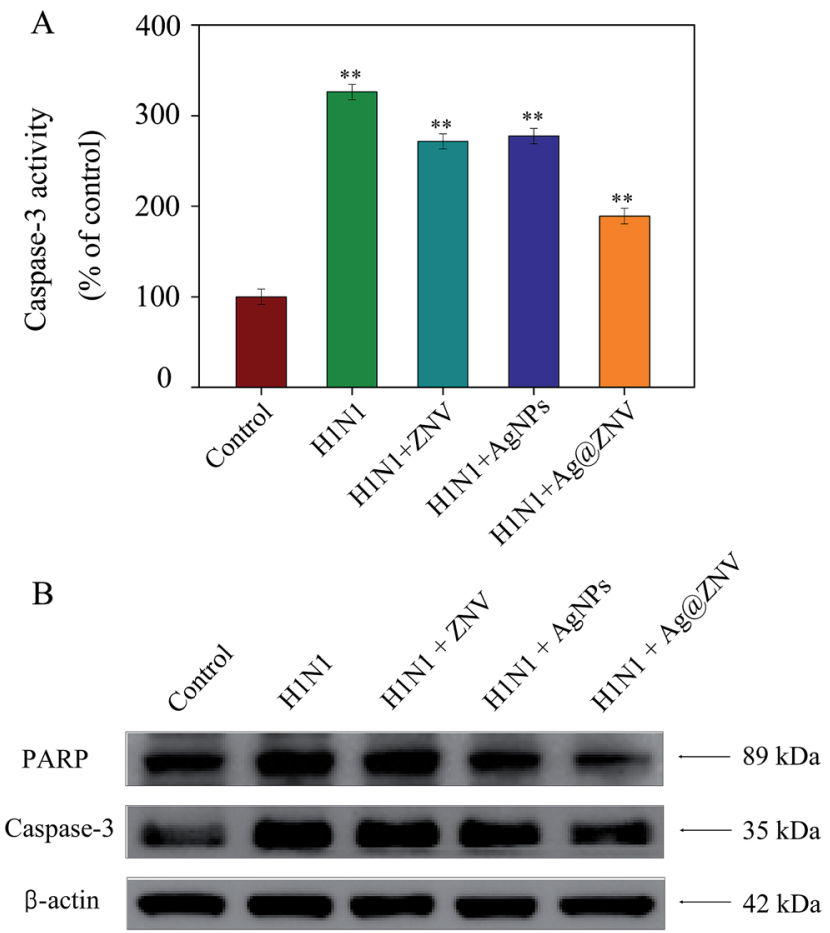

Fig. 6 Inhibition of PARP and caspase- 3 by Ag@ZNV in H1N1 infected MDCK cells. (A) Cells were treated with Ag@ZNV and caspase- 3 activity was detected. (B) Expressing level of PARP and caspase- 3 by western blot, $\beta$-actin was used as loading control. Bars with different characters are statistically different at $P<0.01$ (**) level. The concentrations of Ag@ZNV, AgNPs and ZNV were $2.5 \mu \mathrm{g} \mathrm{ml}^{-1}, 2.5 \mu \mathrm{g} \mathrm{ml}^{-1}$ and $0.8 \mathrm{nM}$. the representative chemical formula of $\mathrm{Ag} @ \mathrm{ZNV}$ is derived as $\left(\mathrm{Ag}_{7} \mathrm{ZNV}\right)_{n}$. The ratio $\mathrm{Ag} / \mathrm{ZNV}$ nanoparticles was followed by previously reported. ${ }^{35,42}$

\subsection{In vitro antiviral activity of Ag@ZNV}

The antiviral activity of AgNPs, ZNV and Ag@ZNV were investigated by MTT assay. The cell viability of AgNPs and ZNV were shown in Fig. 2A and B, AgNPs and ZNV decreased the cell viability in a dose-dependent manner. As shown in Fig. 2C, the concentrations of Ag@ZNV, AgNPs and ZNV were $2.5 \mu \mathrm{g} \mathrm{ml}^{-1}$, $2.5 \mu \mathrm{g} \mathrm{ml}^{-1}$ and $0.8 \mathrm{nM}$. The viability of MDCK cells infected by H1N1 virus was $36.32 \%$. Cells treated with zanamivir and AgNPs reached to $63.23 \%$ and $61.87 \%$ respectively. However, cells treated with Ag@ZNV remarkably reached to 82.26\%. Meanwhile, a evaluation of synergy was performed by previously reported. ${ }^{43}$ The data were interpreted by calculating the fractional inhibitory concentration (FIC) index as follow: FIC= $\left(\mathrm{MIC}_{\mathrm{drug} \text { A combination }} / \mathrm{MIC}_{\text {drug A combination }}\right)+\left(\mathrm{MIC}_{\text {drug B combination }} /\right.$ MIC $\left._{\text {drug B combination }}\right)$. In this study, the FIC index was basically interpreted as follows: a FIC below 0.5, synergism; a FIC between 0.5 and 2.0, indifference, a FIC higher than 2.0, antagonism. MIC drug A combination is concentration present in Ag@ZNV of Ag. MIC drug B combination is concentration present in Ag@ZNV of ZNV. MIC drug A and B alone is that corresponding to "free" AgNPs and ZNV, respectively. The drug combination concentration was detected by ICP, the synergy was evaluated with calculation of in vitro fractional inhibitory concentration index as follow: MIC drug A combination is concentration present in Ag@ZNV of Ag $\left(0.5 \mu \mathrm{g} \mathrm{ml}^{-1}\right)$. MIC drug B combination is concentration present in Ag@ZNV of ZNV
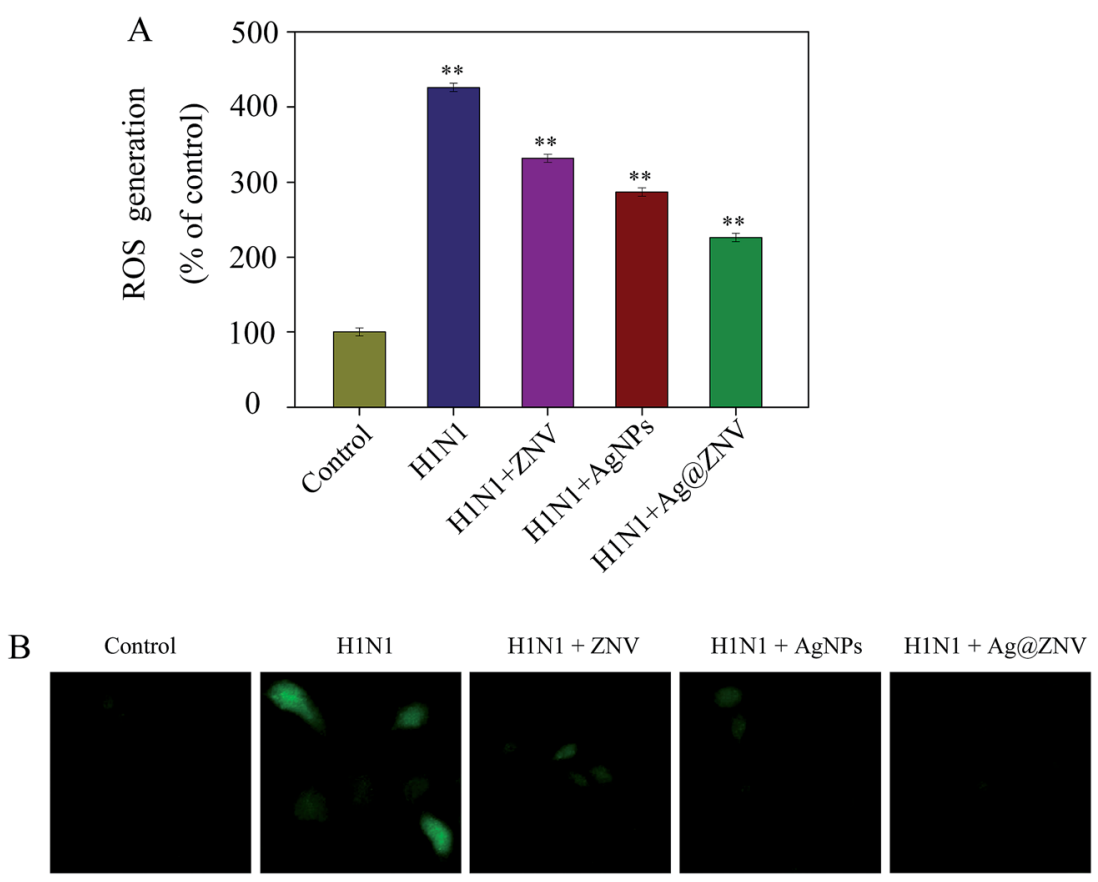

Fig. 7 Restrain of ROS generation by Ag(ZNV in H1N1 infected MDCK cells. (A) ROS levels were detected by DCF fluorescence intensity. (B) Cells were incubated with $10 \mu \mathrm{M}$ DCFH-DA for $30 \mathrm{~min}$ then treated with Ag@ZNV (magnification, $\times 100$ ). Bars with different characters are statistically different at $\left.P<0.01{ }^{* *}\right)$ level. The concentrations of Ag(ZZNV, AgNPs and ZNV were $2.5 \mu \mathrm{g} \mathrm{ml}^{-1}, 2.5 \mu \mathrm{g} \mathrm{ml}{ }^{-1}$ and $0.8 \mathrm{nM}$. 
(0.2 nM). MIC drug A alone is that corresponding to free AgNPs $\left(2.5 \mu \mathrm{g} \mathrm{ml}^{-1}\right)$. MIC drug B alone is that corresponding to free $\mathrm{ZNV}(0.8 \mathrm{nM}) . \mathrm{FIC}=\left(\mathrm{MIC}_{\text {drug A combination }} / \mathrm{MIC}_{\text {drug A combination }}\right)+$ $\left(\mathrm{MIC}_{\text {drug в combination }} / \mathrm{MIC}_{\text {drug в combination }}\right)=0.5 \mu \mathrm{g} \mathrm{ml} \mathrm{ml}^{-1} / 2.5$ $\mu \mathrm{g} \mathrm{m} \mathrm{l}^{-1}+0.2 \mathrm{nM} / 0.8 \mathrm{nM}=0.45$. The FIC was less than 0.5 which indicated the evaluation was synergism. The result suggested that Ag@ZNV effectively enhanced the antiviral activity. As shown in Fig. 2D, MDCK cells infected by H1N1 showed cytoplasmic shrinkage, reduction in cell numbers and loss of cell-to-cell contact. The cytopathic effect was attenuate when treated with Ag@ZNV. The cell viability and images suggested that Ag@ZNV effectively suppressed the H1N1 virus proliferation.

\subsection{Intracellular localization of Ag@ZNV}

Endocytosis against nanoparticles is significant to transmission study of drugs loaded nanosystems. ${ }^{44}$ In the present study, the localization of Ag@ZNV labeled by coumarin-6 in MDCK cells was tracked by simultaneous staining. As Fig. 3 suggested, the yellow area overlap with green and red fluorescence demonstrated the co-localization of Ag@ZNV and lysosomes. The combination accumulated on MDCK cells membrane, then Ag@ZNV escaped from lysosome and released into the cytoplasm after $60 \mathrm{~min}$. The fluorescence intensified gradually displayed time-dependent cell-penetrating for antiviral activity of Ag@ZNV.

\subsection{Neuraminidase activity}

Neuraminidase (NA) activity was used to estimate the effect of viruses from infected cells. Zanamivir is commonly used as NA inhibitors for clinical treatment against influenza virus infection. In this study, we compared the effects of AgNPs, zanamivir and Ag@ZNV on H1N1 NA activity. The data in Fig. 4 showed that Ag@ZNV-treated H1N1 virus had lower NA activity (42.68\%) than that treated with zanamivir (72.42\%) or AgNPs $(58.37 \%)$ alone, suggesting that the compounds were more effective in inhibition on NA activity of H1N1 virus.

\subsection{Suppression of apoptosis by Ag@ZNV}

Flow cytometric analysis and TUNEL-DAPI assay were performed to evaluate the antiviral mechanisms of Ag@ZNV. As shown in Fig. 5A, the sub-G1 apoptotic cell population had a remarkable rise to $29.4 \%$ in the DNA histogram. However, Ag@ZNV significantly reduced it to $17.3 \%$. DNA fragmentation is regarded as a vital biochemical hallmark during cell apoptosis. In Fig. 5B, MDCK cells infected by H1N1 virus presented typical apoptotic features with nuclear condensation and DNA fragmentation. Nevertheless, the DNA fragmentation and changes in nuclear morphology induced by H1N1 virus were effectively resisted when treated with Ag@ZNV. These data indicated that MDCK cells were protected by Ag@ZNV from $\mathrm{H} 1 \mathrm{~N} 1$ virus-induced apoptosis.

\subsection{Inhibition of caspase-3 activation by Ag@ZNV}

Caspase-3 plays as a pivotal executioner role in apoptosis, as it is responsible for the proteolytic cleavage of many critical proteins, such as the poly-ADP-ribose polymerase (PARP). To investigate the activation of caspase- 3 and PARP during inhibition of H1N1 virus by Ag@ZNV, we carried out a fluorometric assay and western blot. As revealed in Fig. 6A, caspase-3 activity of MDCK cells infected by H1N1 virus reached 326\%, while the Ag@ZNV group substantially decreased to 189\%. In Fig. 6B, expressing levels of caspase-3 and PARP in cells treated with Ag@ZNV were downregulated evidently comparing to the up regulation group of cells without treatments post H1N1 infection. The result demonstrated that Ag@ZNV resisted H1N1 virus activity through inhibition of cell apoptotic mediated by caspase-3.

\subsection{Resistance of ROS generation by Ag@ZNV}

Including influenza virus, infections of certain viruses develop simultaneously with the generation of excess reactive oxygen species (ROS) which is associated with cell apoptosis. In order to investigate whether Ag@ZNV nanoparticles restrain ROS-
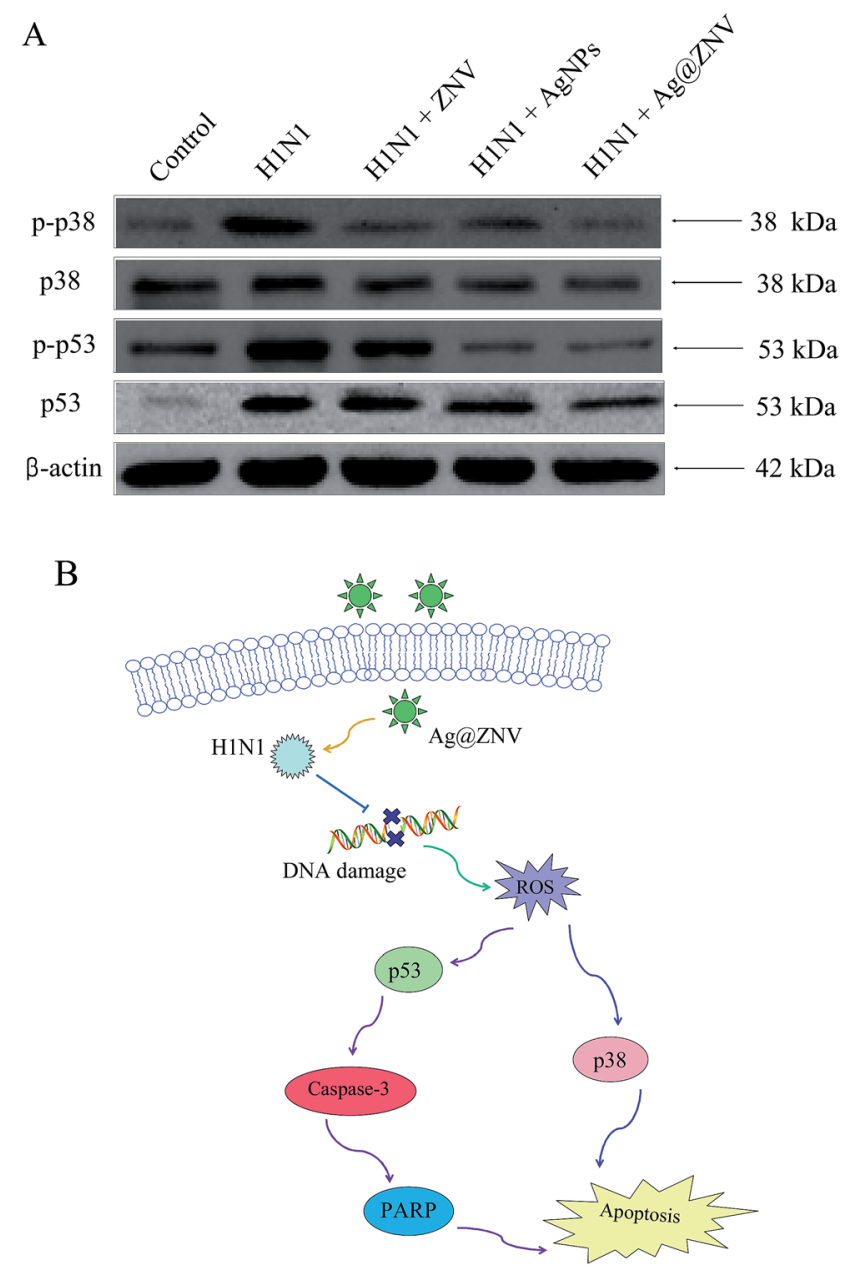

Fig. 8 Inhibition of ROS-mediated apoptosis signaling pathways by Ag@ZNV in H1N1 infected MDCK cells. (A) Inhibition of expressions of p38 and p53 which were up regulated by H1N1 infection. (B) The sketch of ROS-mediated p38 and p53 signaling pathways. The concentrations of Ag@ZNV, AgNPs and ZNV were $2.5 \mu \mathrm{g} \mathrm{ml}^{-1}, 2.5 \mu \mathrm{g}$ $\mathrm{ml}^{-1}$ and $0.8 \mathrm{nM}$. 
mediated apoptosis induced by H1N1 virus. We monitored intracellular ROS level by inspecting the fluorescence intensity of dichlorofluorescein (DCF). As shown in Fig. 7A, ROS generation of MDCK cells heightened obviously post infection of H1N1 virus without treatments. Zanamivir or AgNPs alone inhibited the generation slightly when Ag@ZNV cut it down substantially. From photos in Fig. 7B, we observed strong fluorescent intensity of DCF in MDCK cells infected by H1N1 virus. Fluorescence in cells treated with zanamivir or AgNPs alone turned weak and present dark after treated with Ag@ZNV. These results revealed that Ag@ZNV restrained ROS generation induced by H1N1 virus infection.

\subsection{ROS-mediated signaling pathways}

ROS overproduction causes DNA damage and further leads to cell apoptosis through regulating signaling pathways like p38 and p53. Due to the inhibition of H1N1 virus-induced ROS generation, we further examined the expression of proteins downstream post treated with Ag@ZNV by western blot. As displayed in Fig. 8B, H1N1 infection resulted in up regulations of expressing of p38, p-p38, p53 and p-p53. Oppositely, they were partly down regulated when cells were treated with Ag@ZNV. These results reflected that ROSmediated p38 MAPK and p53 signaling pathways took effect on the inhibition of cells apoptosis induced by H1N1 virus by Ag@ZNV.

\section{Conclusions}

In conclusion, our study demonstrated preparation of zanamivir loaded by silver nanoparticles (Ag@ZNV). Ag@ZNV exhibits superior abilities to improve cellular uptake and resist H1N1 virus infection. The compound evidently depressed the neuraminidase activity of H1N1 virus and reduced the apoptotic cell population induced by H1N1 virus infection. The potential molecular mechanisms revealed that Ag@ZNV inhibited caspase-3 mediated apoptosis via ROS generation. Furthermore, we found that p38 and p53 signaling pathways were associated in down regulating ROS-mediated apoptotic triggered by the Ag@ZNV in MDCK cells post H1N1 virus infection. In summary, our study indicates that Ag@ZNV can effectively protect MDCK cells from apoptosis induced by infection of H1N1 influenza virus.

\section{Conflict of interest}

All the authors report no conflicts of interest in this work.

\section{Acknowledgements}

This work was supported by the China Postdoctoral Science Foundation (2015M582366), the Technology Planning Project of Guangdong Province (2014A020212697), the Technology Planning Project of Guangdong (201607010120).

\section{References}

1 M. Kanekiyo, C. J. Wei, H. M. Yassine, P. M. McTamney, J. C. Boyington, J. R. Whittle, S. S. Rao, W. P. Kong, L. Wang and G. J. Nabel, Nature, 2013, 499, 102-106.

2 N. L. Kallewaard, D. Corti, P. J. Collins, U. Neu, J. M. McAuliffe, E. Benjamin, L. Wachter-Rosati, F. J. Palmer-Hill, A. Q. Yuan, P. A. Walker, M. K. Vorlaender, S. Bianchi, B. Guarino, A. De Marco, F. Vanzetta, G. Agatic, M. Foglierini, D. Pinna, B. Fernandez-Rodriguez, A. Fruehwirth, C. Silacci, R. W. Ogrodowicz, S. R. Martin, F. Sallusto, J. A. Suzich, A. Lanzavecchia, Q. Zhu, S. J. Gamblin and J. J. Skehel, Cell, 2016, 166, 596-608.

3 A. Pizzorno, Y. Abed, C. Rheaume, X. Bouhy and G. Boivin, Antimicrob. Agents Chemother., 2013, 57, 1784-1789.

4 C. I. Barker and M. D. Snape, Lancet, 2014, 14, 227-238.

5 Y. C. Su, J. Bahl, U. Joseph, K. M. Butt, H. A. Peck, E. S. Koay, L. L. Oon, I. G. Barr, D. Vijaykrishna and G. J. Smith, Nat. Commun., 2015, 6, 7952.

6 L. Jiang, G. Fantoni, L. Couzens, J. Gao, E. Plant, Z. Ye, M. C. Eichelberger and H. Wan, J. Virol., 2015, 90, 117-128.

7 R. J. Garten, C. T. Davis, C. A. Russell, B. Shu, S. Lindstrom, A. Balish, W. M. Sessions, X. Xu, E. Skepner, V. Deyde, M. Okomo-Adhiambo, L. Gubareva, J. Barnes, C. B. Smith, S. L. Emery, M. J. Hillman, P. Rivailler, J. Smagala, M. de Graaf, D. F. Burke, R. A. Fouchier, C. Pappas, C. M. AlpucheAranda, H. Lopez-Gatell, H. Olivera, I. Lopez, C. A. Myers, D. Faix, P. J. Blair, C. Yu, K. M. Keene, P. D. Dotson Jr, D. Boxrud, A. R. Sambol, S. H. Abid, K. St George, T. Bannerman, A. L. Moore, D. J. Stringer, P. Blevins, G. J. Demmler-Harrison, M. Ginsberg, P. Kriner, S. Waterman, S. Smole, H. F. Guevara, E. A. Belongia, P. A. Clark, S. T. Beatrice, R. Donis, J. Katz, L. Finelli, C. B. Bridges, M. Shaw, D. B. Jernigan, T. M. Uyeki, D. J. Smith, A. I. Klimov and N. J. Cox, Science, 2009, 325, 197-201.

8 R. Xu, X. Zhu, R. McBride, C. M. Nycholat, W. Yu, J. C. Paulson and I. A. Wilson, J. Virol., 2012, 86, 9221-9232.

9 K. Little, S. K. Leang, J. Butler, C. Baas, B. Harrower, J. Mosse, I. G. Barr and A. C. Hurt, Eurosurveillance, 2015, 20, 1-9.

10 H. Wan, H. Yang, D. A. Shore, R. J. Garten, L. Couzens, J. Gao, L. Jiang, P. J. Carney, J. Villanueva, J. Stevens and M. C. Eichelberger, Nat. Commun., 2015, 6, 6114.

11 S. Duan, E. A. Govorkova, J. Bahl, H. Zaraket, T. Baranovich, P. Seiler, K. Prevost, R. G. Webster and R. J. Webby, Nat. Commun., 2014, 5, 5029.

12 M. M. Kaminski, A. Ohnemus, P. Staeheli and D. Rubbenstroth, J. Virol., 2016, 87, 1912-1915.

13 C. J. Heneghan, I. Onakpoya, M. Thompson, E. A. Spencer, M. Jones and T. Jefferson, BMJ, 2014, 348, g2547.

14 E. J. Park, U. Jeong, C. Yoon and Y. Kim, Environ. Toxicol., 2016, 1-12.

15 H. Hu, L. Li, Q. Guo, S. Jin, Y. Zhou, Y. Oh, Y. Feng, Q. Wu and N. Gu, Food Chem. Toxicol., 2016, 95, 175-187.

16 S. Y. Yang, M. J. Chiu, C. H. Lin, H. E. Horng, C. C. Yang, J. J. Chieh, H. H. Chen and B. H. Liu, J. Nanobiotechnol., 2016, 14, 41 . 
17 B. Zhu, Y. Li, Z. Lin, M. Zhao, T. Xu, C. Wang and N. Deng, Nanoscale Res. Lett., 2016, 11(198), 1-8.

18 B. Xue, D. He, S. Gao, D. Wang, K. Yokoyama and L. Wang, Int. J. Nanomed., 2016, 11, 1899-1906.

19 P. C. Lombardo, A. L. Poli, L. F. Castro, J. R. Perussi and C. C. Schmitt, ACS Appl. Mater. Interfaces, 2016, 8, 21640-21647.

20 S. Gaikwad, A. Ingle, A. Gade, M. Rai, A. Falanga, N. Incoronato, L. Russo, S. Galdiero and M. Galdiero, Int. J. Nanomed., 2013, 8, 4303-4314.

21 X. X. Yang, C. M. Li and C. Z. Huang, Nanoscale, 2016, 8, 3040-3048.

22 V. Sujitha, K. Murugan, M. Paulpandi, C. Panneerselvam, U. Suresh, M. Roni, M. Nicoletti, A. Higuchi, P. Madhiyazhagan, J. Subramaniam, D. Dinesh, C. Vadivalagan, B. Chandramohan, A. A. Alarfaj, M. A. Munusamy, D. R. Barnard and G. Benelli, Parasitol. Res., 2015, 114, 3315-3325.

23 D. Xiang, Y. Zheng, W. Duan, X. Li, J. Yin, S. Shigdar, M. L. O'Connor, M. Marappan, X. Zhao, Y. Miao, B. Xiang and C. Zheng, Int. J. Nanomed., 2013, 8, 4103-4113.

24 B. Borrego, G. Lorenzo, J. D. Mota-Morales, H. AlmanzaReyes, F. Mateos, E. Lopez-Gil, N. de la Losa, V. A. Burmistrov, A. N. Pestryakov, A. Brun and N. Bogdanchikova, Nanomedicine, 2016, 12, 1185-1192.

25 E. K. Elbeshehy, A. M. Elazzazy and G. Aggelis, Frontiers in Microbiology, 2015, 6, 453.

26 J. Geng, X. Sun, P. Wang, S. Zhang, X. Wang, H. Wu, L. Hong, C. Xie, X. Li, H. Zhao, Q. Liu, M. Jiang, Q. Chen, J. Zhang, Y. Li, S. Song, H. R. Wang, R. Zhou, R. L. Johnson, K. Y. Chien, S. C. Lin, J. Han, J. Avruch, L. Chen and D. Zhou, Nat. Immunol., 2015, 16, 1142-1152.

27 H. Kanda, M. Kanao, S. Liu, H. Yi, T. Iida, R. C. Levitt, K. A. Candiotti, D. A. Lubarsky and S. Hao, Gene Ther., 2016, 23, 340-348.

28 X. Lin, R. Wang, W. Zou, X. Sun, X. Liu, L. Zhao, S. Wang and M. Jin, Viruses, 2016, 8, 1-16.

29 Y. Li, Z. Lin, M. Zhao, T. Xu, C. Wang, L. Hua, H. Wang, H. Xia and B. Zhu, ACS Appl. Mater. Interfaces, 2016, 8, 24385-24393.

30 Z. L. Y. Li, M. Zhao, M. Guo, T. Xu, C. Wang, H. Xia and B. Zhu, RSC Adv., 2016, 6, 89679-89686.
31 W. T. Harvey, D. J. Benton, V. Gregory, J. P. Hall, R. S. Daniels, T. Bedford, D. T. Haydon, A. J. Hay, J. W. McCauley and R. Reeve, PLoS Pathog., 2016, 12, e1005526.

32 D. Amatore, R. Sgarbanti, K. Aquilano, S. Baldelli, D. Limongi, L. Civitelli, L. Nencioni, E. Garaci, M. R. Ciriolo and A. T. Palamara, Cell. Microbiol., 2015, 17, 131-145.

33 S. L. Linderman, B. S. Chambers, S. J. Zost, K. Parkhouse, Y. Li, C. Herrmann, A. H. Ellebedy, D. M. Carter, S. F. Andrews, N. Y. Zheng, M. Huang, Y. Huang, D. Strauss, B. H. Shaz, R. L. Hodinka, G. Reyes-Teran, T. M. Ross, P. C. Wilson, R. Ahmed, J. D. Bloom and S. E. Hensley, Proc. Natl. Acad. Sci. U. S. A., 2016, 111, 15798-15803.

34 F. P. Ramanery, A. A. Mansur, H. S. Mansur, S. M. Carvalho and M. C. Fonseca, Nanoscale Res. Lett., 2016, 11(187), 1-12. 35 Y. Li, X. Li, Y. S. Wong, T. Chen, H. Zhang, C. Liu and W. Zheng, Biomaterials, 2011, 32, 9068-9076.

36 S. Wang, H. Li, Y. Chen, H. Wei, G. F. Gao, H. Liu, S. Huang and J. L. Chen, J. Biol. Chem., 2016, 287, 9804-9816.

37 L. Song, Y. Guo, D. Roebuck, C. Chen, M. Yang, Z. Yang, S. Sreedharan, C. Glover, J. A. Thomas, D. Liu, S. Guo, R. Chen and D. Zhou, ACS Appl. Mater. Interfaces, 2015, 7, 18707-18716.

38 A. Karmakar, Y. Xu, T. Mustafa, G. Kannarpady, S. M. Bratton, A. Radominska-Pandya, P. A. Crooks and A. S. Biris, $R S C$ Adv., 2015, 5, 2411-2420.

39 Y. Li, Z. Lin, M. Zhao, T. Xu, C. Wang, H. Xia, H. Wang and B. Zhu, Int. J. Nanomed., 2016, 11, 3065-3076.

40 F. Yang, Q. Tang, X. Zhong, Y. Bai, T. Chen, Y. Zhang, Y. Li and W. Zheng, Int. J. Nanomed., 2012, 7, 835-844.

41 G. Ren, X. Lu, Y. Li, Y. Zhu, L. Dai and L. Jiang, ACS Appl. Mater. Interfaces, 2016, 8, 4118-4125.

42 W. Liu, X. L. Li, Y. S. Wong, W. J. Zheng, Y. B. Zhang, W. Q. Cao and T. F. Chen, ACS Nano, 2012, 6, 6578-6591.

43 Y. Kohno, H. Ohno, Y. Miyazaki, Y. Higashiyama, K. Yanagihara, Y. Hirakata, K. Fukushima and S. Kohno, Antimicrob. Agents Chemother., 2007, 51, 4071-4076.

44 B. He, L. Yuan, W. Dai, W. Gao, H. Zhang, X. Wang, W. Fang and Q. Zhang, Nanoscale, 2016, 8, 6129-6145. 